REVIEW

\title{
Management of asymptomatic carotid stenosis in patients undergoing general and vascular surgical procedures
}

\author{
M Paciaroni, V Caso, M Acciarresi, R W Baumgartner, G Agnelli
}

J Neurol Neurosurg Psychiatry 2005;76:1332-1336. doi: 10.1136/jnnp.2005.066936

Current available data do not seem to support the strategy for carotid endarterectomy prior to surgical intervention in patients with asymptomatic carotid stenosis. However, in patients with coronary artery disease, synchronous carotid endarterectomy and coronary artery bypass grafting should be considered where there is a proven surgical risk of $<3 \%$ with unilateral asymptomatic stenosis $>60 \%$ or bilateral carotid stenosis $>75 \%$ on the same side as the most severe stenosis. Clarification of the optimal strategy requires an adequately powered, multicentre, randomised clinical trial.

See end of article for authors' affiliations

.....................

Correspondence to: $\operatorname{Dr} M$ Paciaroni, Stroke Unit, University of Perugia, Ospedale Silvestrini, Sant'Andrea delle Fratte, Perugia 06126, Italy; mpaciaroni@libero.it

Received 6 March 2005 In revised form 22 April 2005 Accepted 1 May 2005

\section{ASYMPTOMATIC CAROTID ARTERY STENOSIS}

Ultrasound is the primary modality used to screen for the presence of carotid stenosis. In the Framingham Study, the prevalence of significant $(\geqslant 50 \%)$ carotid stenosis determined by duplex ultrasound in patients $>65$ years of age was $7 \%$ in women and $9 \%$ in men. ${ }^{1}$

Carotid artery lesions have an increased prevalence in patients with coronary and peripheral artery disease (PAD). The annual risk of ipsilateral stroke in patients with an asymptomatic $>50 \%$ carotid stenosis is approximately $2-3 \% .^{2-10}$ The risk of ischaemic stroke increases with the severity of stenosis. ${ }^{11}{ }^{12}$ Mackey et $a .{ }^{13}$ found an patients with a stenosis $\geqslant 50 \%$, and $2.8 \%$ among patients with $80-99 \%$ carotid stenosis.

The results of trials assessing carotid endarterectomy (CEA) in patients with asymptomatic stenosis are still a matter of controversy. ${ }^{14}$ Several randomised trials have compared the efficacy and safety of CEA with best medical treatment in patients with asymptomatic carotid stenosis. A meta-analysis consisting of five trials (2440 patients with stenosis $\geqslant 50 \%$ ), showed a significant reduction in the odds of ispilateral stroke plus perioperative stroke or death, corresponding to a $2 \%$ absolute risk reduction over about 3.1 years in patients undergoing CEA. During the immediate postoperative period an increased prevalence of stroke and death among such patients was observed. ${ }^{15}$ The Asymptomatic Carotid Surgery Trial showed that in asymptomatic patients $<75$ years of age with $\geqslant 70 \%$ carotid stenosis, immediate CEA halved the 5 year stroke risk from $\sim 12 \%$ to $\sim 6 \%$. Half of this 5 year benefit included either disabling or fatal strokes. ${ }^{16}$ The American Heart Association Stroke Council has stated that for CEA to be effective in asymptomatic patients, the target for combined perioperative death and stroke rate should be $<3 \% .{ }^{17}{ }^{18}$

The advent of endovascular approaches for the treatment of carotid disease provides another potential mode of intervention. Most data regarding the performance of endovascular carotid procedures are based on case series, surveys, and enrolment of patients in voluntary registries. ${ }^{19-22}$ Several studies are now underway to further evaluate the potential role of carotid angioplasty and stenting in patients with asymptomatic (and symptomatic) carotid stenosis. The SAPPHIRE trial showed that among high risk patients with symptomatic and asymptomatic ( $>50 \%$ and $>80 \%$ respectively) severe carotid artery stenosis, carotid stenting with the use of an embolic protection device was not inferior to CEA. $^{23}$ annual rate of ipsilateral stroke of $1.4 \%$ among

\section{CARDIAC SURGERY AND RISK OF STROKE}

Strokes have been estimated to occur in $0.3-5.2 \%$ of patients after open heart surgery, ${ }^{24} 1.3 \%$ after cardiac catheterisation, ${ }^{25} 0.2-0.3 \%$ after percutaneous transluminal coronary angioplasty, ${ }^{26} 1.4$ $11.0 \%$ after percutaneous transluminal aortic valvuloplasty, $3.2-4.2 \%$ after percutaneous

Abbreviations: $C A B G$, coronary artery bypass grafting; CEA, carotid endarterectomy; PAD, peripheral artery disease; TIA, transient ischaemic attack 
Table 1 Meta-analyses on the risk of stroke, myocardial infarction (MI) and death in patients undergoing CEA and CABG simultaneously or staged

\begin{tabular}{|c|c|c|c|c|}
\hline & $\mathbf{n}$ & Stroke (\%) & MI (\%) & Death (\%) \\
\hline \multicolumn{5}{|c|}{ Simultaneous $C E A+C A B G$} \\
\hline Moore $1995^{18}$ & $\dagger$ & 6 & 5 & 6 \\
\hline Borger $1999^{60 *}$ & 844 & 6 & - & 4.7 \\
\hline Das $2000^{61}$ & 3295 & 3.9 & - & 4.5 \\
\hline Naylor $2003^{62}$ & 7863 & 4.6 & 3.6 & 4.6 \\
\hline \multicolumn{5}{|c|}{ Prior staged $(C E A+C A B G)$} \\
\hline Moore & $\dagger$ & 5 & 11 & 9 \\
\hline Das & 573 & 1.5 & - & 5.9 \\
\hline Naylor & 917 & 2.7 & 6.5 & 3.4 \\
\hline \multicolumn{5}{|c|}{ Reverse staged (CABG+CEA) } \\
\hline Moore & $\dagger$ & 10 & 3 & 4 \\
\hline Das & 83 & 2.4 & - & 4.8 \\
\hline Naylor & 302 & 6.3 & 0.9 & 2.0 \\
\hline \multicolumn{5}{|c|}{ CEA and CABG separately* } \\
\hline Borger* & 920 & 3.2 & - & 2.9 \\
\hline
\end{tabular}

mitral valvuloplasty, ${ }^{28} 9.0 \%$ after cardiac transplantation, ${ }^{29}$ almost $9 \%$ in patients with coronary artery bypass grafting (CABG) $>75$ years of age, and nearly $16 \%$ after valve surgery. ${ }^{30}{ }^{31}$ A prospective multicentre study found that in patients undergoing intracardiac surgery combined with coronary revascularisation, cerebral complications occurred in one of six patients. ${ }^{32}$

Bucerius et $a b^{33}$ analysed the rate of stroke in 16184 patients undergoing cardiac surgery (CABG, beating heart CABG, aortic valve surgery, mitral valve surgery, double or triple valve surgery, CABG and valve surgery). The overall incidence of stroke was $4.6 \%$ but varied between surgical procedures: $\mathrm{CABG} 3.8 \%$, beating heart CABG $1.9 \%$, aortic valve surgery $4.8 \%$, mitral valve surgery $8.8 \%$, double or triple valve surgery $9.7 \%$, CABG and valve surgery $7.4 \%$. Prospective studies of consecutive patients undergoing CABG showed that the risk of major ischaemic stroke is $1-6 \%{ }^{34-37}$ Multiple factors have been associated with an increased risk of stroke in patients undergoing cardiac surgery: age older than 60 years, $\geqslant 50 \%$ carotid stenosis, prior stroke or transient ischaemic attack (TIA), history of congestive heart failure, valvular disease, repeat heart surgery, postoperative atrial fibrillation, bypass time of more than 2 hours, and prior myocardial infarction. ${ }^{38-41}$

\section{THE STROKE RISK FOR CABG PATIENTS WITH CONCOMITANT ASYMPTOMATIC CAROTID ARTERY DISEASE}

The presence of stenosing carotid plaque is predictive of both coronary artery disease and acute coronary events. ${ }^{42}{ }^{43}$ Indeed, Hedblad et $a l^{44}$ found that $50 \%$ of men with asymptomatic carotid artery stenosis had signs or symptoms of ischaemic heart disease. The vascular mortality rate in men with carotid artery disease and concomitant ischaemic heart disease was more than twice as high as in men with carotid stenosis without ischaemic heart disease. In 1546 consecutive CEAs performed in 1238 patients, angina pectoris was present in $17 \%$ (212/1238); a further $32 \%$ (396/1238) of patients had a history of myocardial infarction. ${ }^{45}$

Several studies have suggested that the stroke risk during CABG is related to the degree of carotid stenosis. In a metaanalysis, patients with no significant carotid disease had a $1.9 \%$ risk of stroke, increasing to $3 \%$ in predominantly asymptomatic patients with unilateral $50-99 \%$ stenosis, 5\% in those with bilateral $50-99 \%$ stenoses and $7-11 \%$ in patients with carotid occlusion. ${ }^{46}$ Although these data suggest an association between significant carotid disease and postCABG stroke, no data on the laterality of the events were available. The incidence of carotid artery disease and postoperative cerebrovascular complications were higher in patients who had had revascularisation for stenosis of the left main stem coronary artery. ${ }^{47}$

The risk of major cerebrovascular and cardiovascular complications of atherosclerosis is related more to the stability than to the extent of plaques. The surface morphology of the carotid plaques predicts the risk of coronary events independently of degree of carotid stenosis. ${ }^{48}$ In the European Carotid Surgery Trial and the North American Symptomatic Carotid Endarterectomy Trial, patients with irregular or ulcerated plaques in one or both carotid arteries were more likely to have had previous myocardial infarction than patients with smooth plaques. The aforementioned patients were also twice as likely to suffer a vascular death mainly due to coronary artery disease during follow up..$^{40}$

\section{THE MANAGEMENT OF ASYMPTOMATIC CAROTID ARTERY STENOSIS IN PATIENTS UNDERGOING CABG}

There is no consensus on the management of asymptomatic carotid stenosis in patients undergoing CABG. The efficacy of CEA before or combined with CABG remains controversial (table 1).

A meta-analysis of 56 studies reviewed three operative strategies: simultaneous carotid surgery and CABG, carotid surgery followed by $\mathrm{CABG}$, and CABG followed by carotid surgery in patients with symptomatic and asymptomatic carotid artery disease. ${ }^{18}$ Perioperative stroke rates were $10 \%$ if CABG preceded carotid surgery, and somewhat lower if carotid and coronary surgery were combined $(6 \%)$ and if carotid surgery preceded CABG $(5 \%)$. On the other hand, CEA followed by CABG showed the highest rates for perioperative myocardial infarction (11\%) and death (9\%), whereas simultaneous carotid surgery and CABG and CABG followed by CEA showed lower rates for perioperative myocardial infarction (5\% and 3\%, respectively) and death (6\% and $4 \%$, respectively). ${ }^{18}$

Another meta-analysis covering 16 studies with a total of 844 combined CABG/CEA patients and 920 staged procedures patients revealed a significantly increased risk in the composite endpoint, stroke, or death for patients undergoing combined procedures. The crude event rates for stroke were $6.0 \% v 3.2 \%$ for combined versus staged procedure, $4.7 \% v$ $2.9 \%$, and $9.5 \% \vee 5.7 \%$ for stroke and death. ${ }^{51}$

Das et $a l^{52}$ performed an analytical overview of the strategies for the management of concomitant coronary 
artery disease and asymptomatic carotid artery stenosis $(>50 \%)$. Four strategies were analysed: CABG in the presence of carotid stenosis, combined CEA and CABG, reverse ( $\mathrm{CABG}+\mathrm{CEA}<3$ months) and prior staged (CEA + CABG $<3$ months). Comparative analysis indicated a significant reduction in stroke for prior versus combined procedures $(1.5 \% \quad v 3.9 \%, \mathrm{p}=0.007$, odds ratio $(\mathrm{OR})=0.39,95 \%$ confidence interval (CI) 0.2 to 0.7 ) with a higher mortality $(5.9 \% v 4.5 \%, \mathrm{p}=0.1, \mathrm{OR}=1.41, \mathrm{CI} 0.96$ to 2.06$)$. The stroke rate in the prior stage also remained significantly lower compared with the other two groups but when total risks for stroke and death were analysed, similar results were found among the groups: prior $7.4 \%$, reverse stage $7.2 \%$, combined $8.4 \%$ and $11.5 \%$ in CABG in the presence of carotid stenosis.

In another systematic review, ${ }^{53}$ the outcomes following staged or synchronous procedures in several studies were analysed, with 94 studies having synchronous CEA+CABG and 24 staged CEA-CABG. About $60 \%$ of patients undergoing staged/synchronous procedures were neurologically asymptomatic, while $30-37 \%$ had bilateral $50-99 \%$ stenosis or controlateral occlusion. The majority of synchronous cases (72\%) were New York Heart Association grade 3 or $4 ; 39 \%$ of these were classed as "urgent" while left mainstem disease was present in $\sim 25 \%$. Operative mortality was highest in patients undergoing synchronous CEA+CABG $(4.6 \%, 95 \%$ CI 4.1 to 5.2 ). Reverse staged procedures (CABG-CEA) were associated with the highest risk of both ipsilateral stroke $(5.8 \%, 95 \%$ CI 0.0 to 14.3$)$ and any stroke $(6.3 \%, 95 \%$ CI 1.0 to 11.7). The risk of any operative stroke was lowest following staged CEA-CABG $(2.7 \%, 95 \%$ CI 1.6 to 3.9$)$. The risk of myocardial infarction was lowest following reverse staged procedures $(0.9 \%, 95 \%$ CI 0.5 to 1.4$)$ and highest in patients undergoing staged CEA-CABG $(6.5 \%$, 95\% CI 2.9 to 10$)$. Death and any stroke were highest in patients undergoing synchronous CEA+CABG $(8.7 \%, 95 \%$ CI 7.7 to 9.8$)$ and lowest following staged CEA-CABG (6.1\%, 95\% CI 2.4 to 9.2). However, the benefit conferred by staging the operation was reduced when the risk of myocardial infarction was subsequently included in the analysis (synchronous $=11.5 \%, 95 \%$ CI 10.1 to 12.9 ; staged CEA-CABG $=10.2 \%$, 95\% CI 7.4 to 13.1).

A multistate population based study was undertaken to evaluate both the community wide outcomes of combined CEA and CABG and the risk for adverse events. In total, 10561 CEAs were randomly selected, of which 226 procedures were performed in combination with CABG in the same operative event. Only $12 \%$ of patients undergoing CEA/ CABG had had recent ipsilateral stroke or TIA, while $56 \%$ had had an asymptomatic carotid stenosis. The combined stroke and death rate was $17.7 \%$. Proximal aortic arch atherosclerosis and symptomatic carotid stenosis were associated with stroke $(\mathrm{p}<0.05)$. Female sex, emergent operation, reperformed $\mathrm{CABG}$, blood pressure on pump, total pump time, presence of left main disease and number of diseased coronaries were associated with higher mortality $(p<0.05)$. Strokes appeared to be associated with operative events, but diagnosis was delayed and post-event carotid patency was not documented. Most strokes did not occur in the ipsilateral hemisphere of the CEA. ${ }^{54}$

The aforementioned data do not support the strategy for CEA prior to CABG in patients with asymptomatic carotid stenosis. The patient subset with severe stenosis (especially $>90 \%$ ) or occlusion, or bilateral occlusive disease is likely to represent a special circumstance, especially in patients with poor collateral circulation. ${ }^{55}$ In some patients, the reduction in cerebral perfusion distal to a tight carotid stenosis or occlusion could be an important factor leading to the development of ischaemic stroke. In these patients, cerebral perfusion reserve ipsilateral to the carotid stenosis should be performed using: transcranial Doppler sonography or single photon emission computed tomography after administration of acetazolamide, ${ }^{133}$ Xe radionuclide CT, functional magnetic resonance imaging and positron emission tomography.$^{56-58}$ Magnetic resonance spectroscopy showed that such patients have metabolic changes in the affected hemisphere, which are consistent with a chronic ischaemia in the absence of cerebral infarction..$^{59}$ When the cerebral autoregulation is impaired, the simultaneous intervention (CEA/CABG) should be considered because patients with cerebral hypoperfusion and ischaemic metabolic changes distal to severe carotid stenosis are probably at high risk for stroke during CABG. Unfortunately, no clinical trial has proven this hypothesis. In patients with bilateral $>75 \%$ carotid stenosis, Caplan et $a l^{57}$ recommended simultaneous CABG and CEA on the side of the more severe stenosis.

The American Heart Association (AHA) has published guidelines regarding the appropriateness of synchronous CABG+CEA in CABG patients with asymptomatic occlusive carotid disease. The consensus view is that synchronous CEA+CABG is "acceptable but not proven" in patients with unilateral $>60 \%$ asymptomatic stenosis where there is a proven operative stroke and death risk of $<3 \%$. In those units with an operative stroke and death risk $>3 \%$, the guidelines qualified the appropriateness of synchronous procedures as "uncertain". ${ }^{60}$

In spite of the aforementioned AHA recommendations, the most favourable surgical management of patients with $>60 \%$ asymptomatic carotid stenosis planning to undergo CABG remains unclear. Clarification of the optimal strategy requires an adequately powered, multicentre, randomised clinical trial. $^{57}$

Regarding new endovascular approaches, the SAPPHIRE trial showed that in high risk patients with asymptomatic severe $(>80 \%)$ carotid artery stenosis, carotid stenting with the use of an embolic protection device was not inferior to CEA. Patients with previous CABG were the major population enrolled in the study. ${ }^{23}$ This strategy could be an alternative procedure to CEA in the future.

\section{NON-CARDIAC SURGERY AND RISK OF STROKE}

Stroke after general surgical procedures is reported to be $<1 \%{ }^{61}$ Parikh et $a l^{62}$ reported that $19(0.08 \%)$ of 24641 general and vascular surgical procedure patients suffered a perioperative stroke. The significant factors contributing to perioperative stroke included: hypertension, smoking, earlier neurological symptoms, and an abnormal rhythm on electrocardiogram. The most common factor for stroke was atrial fibrillation.

Perioperative stroke and other complications can be related to atherosclerosis, although there is no evidence that asymptomatic carotid artery stenosis predictably increases stroke risk during aortoiliac surgery. ${ }^{63}$ Barnes and Marszalek $^{65}$ found in a prospective study that perioperative mortality in PAD patients was higher in the presence of carotid obstruction found by ultrasound. Deaths were primarily due to myocardial infarction. Gerraty et $a t^{66}$ described asymptomatic $\geqslant 50 \%$ stenosis or occlusion of the carotid in 53 patients, including 28 cases with $\geqslant 80 \%$ stenosis or occlusion, who had peripheral vascular procedures. There was no perioperative stroke on the side of carotid obstruction. Cardiac embolism, hypotension, and perioperative hypercoagulable state could have been the other stroke mechanism involved.

In order to define the management of patients with PAD and concomitant carotid stenosis, Bower ${ }^{67}$ reviewed the stroke risk in 121 patients undergoing both CEA and abdominal aortic reconstruction. Of these 59 had had an asymptomatic carotid stenosis at the time of the first 
operation: 44 had had CEA before abdominal aortic reconstruction (group I) and 15 had had aortic surgery before CEA (group II). In group II, two patients had a postoperative stroke and six developed TIAs in the interval between operations. Seven patients (47\%) remained asymptomatic between the procedures. In comparison, only two (5\%) of the 44 asymptomatic patients in group I developed TIAs in the interval between operations, and only one was on the CEA side. The other 42 (95\%) patients remained asymptomatic.

Additionally, in general elective surgery several studies have failed to demonstrate a correlation between severe asymptomatic carotid stenosis and incidence of perioperative stroke. Ropper et al ${ }^{68}$ prospectively examined 735 unselected patients undergoing elective surgery to determine the incidence of carotid bruit and postoperative stroke. In 104 patients (14\%) with bruits, only 1 had a stroke within 3 days after the operation, while in 631 patients without a bruit, 4 had a stroke within that time. The overall incidence of stroke was $0.7 \%$ and did not differ between the groups.

The stroke risk related to asymptomatic carotid stenosis in patients undergoing non-cardiac surgery is low. There is no evidence to support prophylactic CEA.

\section{CONCLUSION}

At present, there are no clearly defined indications for managing asymptomatic carotid stenosis in patients undergoing general and vascular surgical procedures.

Based on the data described, we suggest the following recommendations:

- In patients with asymptomatic internal carotid artery stenosis $(>50 \%)$ planned to undergo general surgery, available data do not support performing CEA prior to surgical intervention.

- In patients with unilateral asymptomatic internal carotid artery stenosis $(>60 \%)$ planned to undergo CABG, synchronous CEA+CABG is an acceptable option but has not yet been proven. Perioperative stroke and death risk must be $<3 \%$ and life expectancy at least 5 years to justify the procedure.

- In patients with bilateral internal carotid artery stenosis $(>75 \%)$ planned to undergo CABG, synchronous CEA (on the side of the more severe stenosis) + CABG is an acceptable option but has not been proven to date. Perioperative stroke and death risk must be $<3 \%$ and life expectancy at least 5 years to justify the procedure.

- In patients with internal carotid artery stenosis (>60\%) and contralateral occlusion planned to undergo CABG, available data do not support performing CEA prior to surgical intervention.

- In the aforementioned patients planned to undergo CABG, carotid stenting could be a therapeutic alternative but no study has examined this issue.

\section{Authors' affiliations \\ M Paciaroni, V Caso, M Acciarresi, G Agnelli, Stroke Unit, University Hospital of Perugia, Italy \\ R W Baumgartner, Department of Neurology, University Hospital of Zürich, Switzerland \\ Competing interests: none declared \\ REFERENCES \\ 1 Fine-Edelstein JS, Wolf PA, O'Leary DH, et al. Precursors of extracranial carotid atherosclerosis in the Framingham Study. Neurology 1994;44:1046-50. \\ 2 Meissner I, Weibers DO, Whisnant JP, et al. The natural history of asymptomatic carotid artery occlusive lesions. JAMA 1987;258:2704-7.}

3 Hennerici $\mathrm{M}$, Hulsbomer $\mathrm{HB}$, Hefter $\mathrm{H}$, et al. Natural history of asymptomatic extracranial arterial disease. Brain 1987;110:777-91.

4 Norris JW, Zhu CZ, Bornstein NM, et al. Vascular risks of asymptomatic stenosis. Stroke 1991;22:1485-90.

5 European Carotid Surgery Trialist's (ECST) Collaborative Group. MRC European Carotid Surgery Trial: interim results for symptomatic patients with severe (70-99\%) or with mild (0-29\%) carotid stenosis. Lancet 1991;337:1235-43

6 Hobson RW, Weiss DG, Fields WS, et al. Veterans Affairs Cooperative Study Group: efficacy of carotid endarterectomy for asymptomatic carotid stenosis. N Engl J Med 1993;328:221-7.

7 Asymptomatic Carotid Atherosclerosis Study (ACAS). Endarterectomy for asymptomatic carotid artery stenosis. JAMA 1995;273:1421-8.

8 Cote R, Battista RN, Abrahamowicz M, et al. Lack of effect of aspirin in asymptomatic patients with carotid bruits and substantial carotid narrowing Ann Intern Med 1995; 123:649-55.

9 Johnson BF, Verlato F, Bergelin RO, et al. Clinical outcome in patients with mild and moderate carotid artery stenosis. J Vasc Surg 1995;21:120-6.

10 Inzitari D, Eliasziw $M$, Gates $P$, et al. The causes and risk of stroke in patients with asymptomatic internal carotid artery stenosis. North American Symptomatic Carotid Endarterectomy Trial Collaborators. N Engl J Med 2000;342: 1693-700.

11 Chambers BR, Norris NW. Outcome in patients with asymptomatic neck bruits. N Engl J Med 1986;315:860-5.

12 Rothwell PM, Slattery J, Warlow CP, on behalf of the ECST Collaborators. Risk of stroke in the distribution of an asymptomatic carotid artery. Lancet 1995:345:209-12

13 Mackey AE, Abrahamowicz $M$, Langlois $Y$, et al. Outcome of asymptomatic patients with carotid disease. Neurology 1997;48:896-903.

14 Barnett HJM, Meldrum HE. The outlook for patients with carotid stenosis. Cerebrovasc Dis 2000;10(suppl 4):30-5.

15 Benavente O, Moher D, Pham B. Carotid endarterectomy for asymptomatic carotid stenosis: a meta-analysis. BMJ 1998;317:1477-80.

16 Halliday A, Mansfield A, Marro J, MRC Asymptomatic Carotid Surgery Trial (ACST) Collaborative Group, et al. Prevention of disabling and fatal strokes by successful carotid endarterectomy in patients without recent neurological symptoms: randomised controlled trial. Lancet 2004;8:1491-502.

17 Beebe HG, Glagett GP, Deweese JA, et al. Assessing risk associated with carotid endarterectomy: a statement for health professionals by an ad hoc committee on carotid surgery standards of the Stroke Council American Heart Association. Circulation 1989:79:472-3.

18 Moore WS, Barnett HJM, Beebe HG, et al. Guidelines for carotid endarterectomy. A multidisciplinary consensus statement from the $\mathrm{Ad} \mathrm{Hoc}$ Committee, American Heart Association. Stroke 1995;26:188-201.

19 Wholey MH, Wholey M, Mathias K, et al. Global experience in cervical carotid artery stent placement. Cathet Cardiovasc Intervent 2000;50:160-7.

20 Hobson RW 2nd, Lal Bk, Chakhtovra E, et al. Carotid artery stenting: analysis of data for 105 patients at high risk, J Vasc Surg 2003;37:1234-9.

21 McKevitt FM, Sivagurun A, Venables GS, et al. Effect of treatment of carotid artery stenosis on blood pressure: a comparison of hemodynamic disturbances after carotid endarterectomy and endovascular treatment. Stroke 2003;34:2576-81

22 Debette S, Henon H, Gauvrit JY, et al. Angioplasty and stenting for highgrade internal carotid artery stenosis: safety study in 39 selected patients. Cerebrovasc Dis 2004;17:160-5.

23 Yadav JS, Whole MH, Kuntz RE, et al. Protected carotid-artery stenting versus endarterectomy in high-risk patients. N Engl J Med 2004;351:1493-501.

24 Sila C. Neuroimaging of cerebral infarction associated with coronary revascularization. AJNR 1991;12:817-18.

25 Davidson CJ, Mark DB, Pieper KS, et al. Thrombotic and cardiovascular complications related to non-ionic contrast media during cardiac catheterization: analysis of 8517 patients. Am J Cardiol 1990;65:1481-4.

26 Galbreath C, Salgado ED, Furlan AJ, et al. Central nervous system complications of percutaneous transluminal coronary angioplasty. Stroke 1986;17:616-19.

27 Davidson CJ, Skelton TN, Kisslo KB, et al. The risk of systemic embolization associated with percutaneous balloon valvuloplasty in adults. Ann Intern Med 1988; 108:557-60.

28 Nishimura RA, Holmes DR, Ruder GS. Percutaneous balloon valvuloplasty. Mayo Clin Proc 1990;65:198-220.

29 Hotson JR, Pedley TA. The neurologic complications of cardiac transplantation. Brain 1976;99:673-94.

30 Craver JM, Weintraub WS, Jones EL, et al. Predictors of mortality, complications and length of stay in in aortic valve replacement for aortic surgery. Circulation 1988;78(suppl 1):85-90.

31 Wareing TH, Davila-Roman VG, Daily BB, et al. Strategy for the reduction of stroke incidence in cardiac surgical patients. Ann Thorac Surg 1993:55:1400-8.

32 Wolman RL, Nussmeier NA, Aggarwal A, et al. Cerebral injury after cardiac surgery: identification of a group at extraordinary risk. Multicenter Study of Perioperative Ischemia Research Group (McSPI) and the Ischemia Research Education Foundation (IREF) Investigators. Stroke 1999;30:514-22.

33 Bucerius J, Gummert JF, Borger MA, et al. Stroke after cardiac surgery: a risk factor analysis of 16,184 consecutive adult patients. Ann Thorac Surg Feb, 2003;75:472-8.

34 Brever A, Furlan A, Hanson M, et al. Central nervous system complications of coronary artery bypass graft surgery: prospective analysis of 421 patients. Stroke 1983; 14:682-7.

35 Coffey CE, Massey EW, Roberts KB, et al. Natural history of cerebral complications of coronary artery bypass graft surgery. Neurology 1983;33:1416-21. 
36 Shaw $\mathbf{P}$, Bates $D$, Cartlidge $N$, et al. Early neurological complications of coronary artery bypass surgery. Br Med J 1985;291:1384-7.

37 Roach G, Kanchuger M, Mangano C, et al. Adverse cerebral outcomes after coronary bypass surgery. Multicenter Study of Perioperative Ischemia Research Group and the Ischemia Research and Education Foundation Investigators. N Engl J Med 1996;335:1857-63.

38 Reed GL, Singer DE, Picard EH, et al. Stroke following coronary artery bypass surgery. N Engl J Med 1988;319:1246-50.

39 Ricotta JJ, Faggioli GL, Castilone A, et al. Risk factors for stroke after cardiac surgery: Buffalo Cardiac Cerebral Study Group. J Vasc Surg. 1995;21: 35963 (discussion 364).

40 Libman RB, Wirkowski E, Neystat M, et al. Stroke associated with cardiac surgery. Determinants, timing, and stroke subtypes. Arch Neurol 1997;54:83-7.

41 Barbut D, Caplan LR. Brain complications of cardiac surgery. Curr Probl Cardiol 1997;22:447-76.

42 Nowak J, Nilsson T, Sylen C, et al. Potential of carotid ultrasonography in the diagnosis of coronary artery disease. A comparison with exercise test and variance ECG. Stroke 1998;29:439-46.

43 Giral P, Bruckert E, Dairou F, et al. Usefulness in predicting coronary artery disease by ultrasonic evaluation of the carotid arteries in asymptomatic hypercholesterolemic patients with positive exercise stress tests. Am J Cardiol 1999;84:14-17.

44 Hedblad B, Janzon L, Jungquist $G$, et al. Factors modifying the prognosis in men with asymptomatic carotid artery disease. J Int Med 1998;243:57-64.

45 Ennix CL Jr, Lawrie GM, Morris GC Jr, et al. Improved results of carotid endarterectomy in patients with symptomatic coronary disease: an analysis of 1546 consecutive carotid operations. Stroke 1979;10:122-5.

46 Naylor AR, Mehta Z, Rothwell PM, et al. Carotid artery disease and stroke during coronary artery bypass: a critical review of the literature. Eur J Vasc Endovasc Surg 2002;23:283-94.

47 Vigneswaran WT, Sapsford RN, Stanbridge RDL. Disease of the left main coronary artery: early surgical results and their association with carotid artery stenosis. Br Heart J 1993:70:342-5.

48 Rothwell PM, Slattery J, Warlow CP, on behalf of the ECTS Collaborators. Risk of stroke in the distribution of an asymptomatic carotid artery. Lancet 1995;345:209-12.

49 Rothwell PM, Villagra R, Gibson R, et al. Evidence of a chronic systemic cause of instability of atherosclerotic plaques. Lancet 2000;355:19-24.

50 Rothwell PM, Gibson R, Fox AJ, et al. Systemic predisposition to carotid plaque surface irregularity and coronary vascular death. Stroke 2000;31:70.

51 Borger MA, Fremes SE, Welsel RD, et al. Coronary bypass and carotid endarterectomy: does a combined approach increase risk? A meta-analysis. Ann Thorac Surg 1999;68:14-20.
52 Das SK, Brow TD, Peper J. Continuing controversy in the management of concomitant coronary and carotid disease: an overview. Int J Cardiol 2000;74:47-65.

53 Naylor AR, Cuffe RL, Rothwell PM, et al. A systematic review of outcomes following staged and synchronous carotid endarterectomy and coronary artery bypass. Eur J Vasc Endovasc Surg 2003;25:380-9.

54 Brown KR, Kresowik TF, Chin MH, et al. Multistate population-based outcomes of combined carotid endarterectomy and coronary artery bypass. J Vasc Surg Jan, 2003;37:32-9.

55 Sila CA. Neurologic complications of vascular surgery. Neurol Clin 1998; 16:9-20.

56 Chimonitz M, Furlan A, Jones S, et al. Transcranial Doppler assessment of cerebral perfusion reserve in patients with carotid occlusive disease and no evidence of cerebral infarction. Neurology 1993;43:353-7.

57 In: Caplan LR, Hurst JW, Chimowitz MI, eds. Neurological complications of surgery. In: Clinical neurocardiology. New York: Marcel Dekker, 1999:226-97.

58 Takeuchi K, Maida K, Yoshida S, et al. Preoperative cerebrovascular screening before cardiovascular surgery in a high risk area of cerebrovascular events in Japan. J Cardiovasc Surg 2000;41:911-14.

59 Van Der Grond J, Balm R, Kappelle J, et al. Cerebral metabolism of patients with stenosis or occlusion of the internal carotid artery: a 1H-MR spectroscopic imaging study. Stroke 1995;26:822-8.

60 Biller J, Feinberg W, Castaldo JE, et al. Guidelines for carotid endarterectomy. A Statement for healthcare professionals from a special writing group of the Stroke Council, American Heart Association. Stroke 1998;29:554-62.

61 Larsen SF, Zaric D, Boysen G. Postoperative cerebrovascular accidents in general surgery. Acta Anesthesiol Scand 1988;32:698-701.

62 Parikh S, Cohen JR. Perioperative stroke after general surgical procedures. NY State J Med 1993;93:162-5.

63 Carney WI, Stewart WB, De Pinto DJ, et al. Carotid bruit as a risk factor in aortoiliac reconstruction. Surgery 1977;81:567-70.

64 Harris EJ, Moneta GL, Yeager RA, et al. Neurologic deficits following non carotid vascular surgery. Am J Surg 1992;163:537-40

65 Barnes RW, Marszalek PB. Asymptomatic carotid disease in the cardiovascular surgical patients: is prophylactic endarterectomy necessary? Stroke 1981:12:497-500.

66 Gerraty RP, Gates PC, Doyle JC. Carotid stenosis and perioperative stroke risk in symptomatic and asymptomatic patients undergoing vascular or coronary surgery. Stroke 1993;24:1115-18.

67 Bower TC, Merrel SW, Cherry KJ Jr, et al. Advanced carotid disease in patients requiring aortic reconstruction. Am J Surg 1993;166:146-51.

68 Ropper AH, Wwchsler LR, Wilson LS. Carotid bruit and the risk of stroke in elective surgery. N Engl J Med 1982;307:1388-90. 